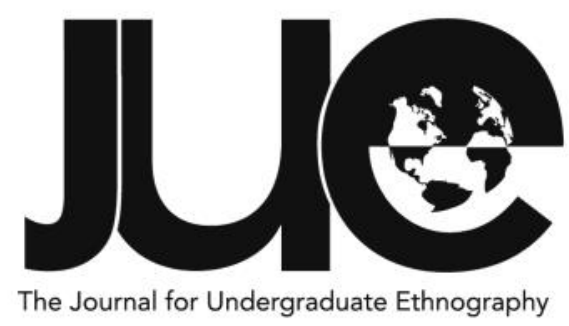

\title{
Picturing Halifax: Young Immigrant Women and the Social Construction of Urban Space
}

\section{Sarah England}

\section{Dalhousie University, sarahfengland@gmail.com}

\section{ABSTRACT}

This study explores the social construction of space in the lives of young immigrant women. Drawing upon data from photoelicitation interviews, I analyze how young women who recently immigrated to Canada interpret and transform the meanings of spaces in their everyday lives. Using the social construction of space as a conceptual framework, I demonstrate how the social positions of young immigrant women are reflected in and negotiated through their use of urban space. While participants share perceptions of risk and experiences of gendered safety issues, all negotiate these issues by gaining spatial knowledge through exploration. They all also experience Otherness in various spaces. However, they construct belonging by developing diverse social networks, claiming space, and getting involved in the international community. It is evident that the city affects how, and whether, young immigrant women mobilize their identities as immigrants. New spaces bring new understandings of their identities as women, young people, and immigrants. This study illuminates how young immigrant women transform cities, and how, in turn, the city transforms them. 


\section{Introduction: Addressing the rise of diversity}

T he experience of the city is not entirely individualized. Gender, ethnicity, age, class, and cultural values are all elements that influence how one interprets and navigates urban space. However, people also exist as social agents who construct and shape their own unique meanings within those spaces (Low 1996b). Spaces are reconfigured, interpreted, and experienced differently according to people's social positions. The accelerated mobility brought by globalization has saturated urban space with diverse everyday encounters that transform both the city and the people living in it. Immigration and its by-product of 'urban multiculture' have been positioned as exterior forces imposing on the fabric of countries and the cities within them (Hall 2015, 854). However, immigration is not best understood as invasive reconfiguration (Hall 2015); rather, immigrants actively shape urban space while negotiating the difference that characterizes their everyday lives.

Globalization continues to bring an increase of urbanization and diversity to Canada, with 95 per cent of immigrants choosing to live in cities (Statistics Canada 2011) and immigration targets increasing to 320,000 newcomers settling in 2017 (Statistics Canada 2016). Young immigrant women settling in Canadian cities contend with the intersection of age, gender, and immigrant status as social positions that shape encounters with their urban environment. Facing numerous transitions, young immigrant women are required to 'grow up' and 'adapt' while establishing jobs, social networks, new understandings of gender, mobility, identities, and new modes of being. Debates in feminist theory have highlighted the need to incorporate intersectionality into analysis, meaning it is vital to address the overlap of multiple social positions such as gender, race, age, and class (Maynard 1994, 2002). Although more and more studies within urban anthropology address intersections of youth, race, gender, and urban space, the integration of the immigrant experience with these social positions is underdeveloped. More generally, youth studies only weakly addresses intersectionality (Green and Singleton 2006). This study addresses the need to incorporate young immigrant women's voices, particularly those who have settled recently, into social research by examining the intersections of gender, age, and the immigrant experience within urban space. Young immigrant women's voices must be brought to the forefront of urban policy in order to work towards a city that accommodates all people. This leads to my research question: how do young immigrant women socially construct space in Halifax, Nova Scotia?

To address this question, I use photoelicitation interviews to illuminate the experiences of eight young immigrant women who have immigrated to Canada in the last eight years. Through this participatory approach, I explore how young immigrant women construct 'belonging' in their new city, and how the experience of space in Halifax compares to the participants' country of origin. Situated in broader discussions in urban anthropology and geography, this study looks at how young immigrant women shape the urban landscape, and in turn, how the urban landscape shapes them. As defined by Low (1996a), the social construction of space is the "phenomenological and symbolic experience of space as mediated by social processes such as exchange, conflict, and control" (861). I use this key concept to gather insight into the way young immigrant women experience and transform space in Halifax, a coastal city in Nova Scotia, Canada that is relatively small yet is also the economic and cultural hub of the Atlantic region. According to the National Household Survey of 2011 (Statistics Canada 2013), Halifax has an immigrant population of 31,245 , which is 8.1 per cent of the total population. 
This article begins with an overview of the social construction of space as a conceptual framework and draws on studies that give insights into gender, age, the immigrant experience, and urban space. Second, it outlines the study's methodology. Third, it explores how perceptions of risk affect participants' experience of space, and how participants negotiate gendered safety issues by developing spatial knowledge. Fourth, I discuss how women navigate encounters with Otherness through sociability, renewing international networks, diversity, and claiming space. Lastly, I examine the ways in which young immigrant women access and mobilize new identities as immigrants, women, and young people through their use of space.

\section{The Social Construction of Space: Gender, Age, and the Immigrant Experience}

The notion that space is simply a passive, neutral setting in which things occur has been problematized in urban anthropology and geography. Places are not "inert containers", but rather "politicized, culturally relative, historically specific, local and multiple constructions" (Rodman 1992, 641). Rather than being viewed as a static backdrop to key events, place needs to be conceptualized. Addressing this need, the social construction of space is a way in which locality is accounted for and theorized. The social construction of space is a transformative process conducted through people's "social exchanges, memories, images, and daily use of the material setting" (Low 1996a, 862). Therefore, space has multiple meanings for different people. Employing the social construction of space as a conceptual framework can both "contextualize the forces" that construct it (Low 1996a, 862), and illuminate the experiences of social actors who construct their own meaningful realities. Thus, examining how young immigrant women socially construct space shapes new understandings of immigrant settlement and integration in Canada.

\section{Gender and Urban Space}

For Massey (1994), places themselves are not only gendered in the messages they transmit and relations they form, but they also "reflect and affect the ways in which gender is constructed and understood" (179). As a result of the gendered public-domestic dichotomy, Massey (1994) outlines that women's identities are restricted as a consequence of their constrained spatial mobility. However, this spatial dichotomy is contested by the inadequacies between gender ideology and its ability to provide an accurate picture of women's realities (Brettell and Sargent 2013). In other words, although women are in principle limited by spatial gendered restraints, reality is more convoluted. In a participatory photo project in Sweden, migrant women took photos of inclusive spaces in their lives. Many photos were taken at school, with groups of culturally diverse female friends, leading researchers to infer that the notion of belonging in space for migrant women is highly gendered. They state, "when considering gender as one of a series of social identities, the gendered space that exists between sameness and otherness is one where gender might be used as a rallying point for the common interests of women" (610). This underscores the need to examine the role gender plays in the construction of belonging for newcomer women.

\section{Youth and Urban Space}

Although often seen as "passive recipients of social transformations" (Nayak 2003, 167), young people are powerful social agents producing their own spatial knowledge and identity. Aiming to address the lack of focus on young people in urban studies, Skelton (2013) demonstrates the importance of young people's mobility in identity formation through a case study of Auckland, New Zealand. She argues that for young people, whose lives are typically characterized by transitional periods, mobility between different spaces is integral to achieving independence, sustaining relationships, and 'growing up' (Skelton 2013). The strength of Skelton's (2013) argument stems from the 81 semi-structured interviews conducted with young urban dwellers, allowing them to describe their subjective experiences. Skelton shows how "the city is constituted at the street level through footsteps" (Skelton 2013, 468), a perspective I adopt in this study. 
Immigrant Experience and Urban Space

Immigration brings diversity to the social exchanges of everyday life and functions as an integral part of urban transformation (Hall 2015). Hall (2015) argues that the key to understanding urbanization and migration lies in understanding these processes as "participatory rather than an invasive" (854) processes of change. Using the London as a case study, Hall (2015) discovers that constructing a sense of belonging is not a process of cultural acceptance, but rather an engaged negotiation of diversity within the framework of inequality. Hall (2015) emphasizes that examining the 'ordinary' and 'everyday' opens new understandings of immigration as "part of the lived processes of societal change" (855). Hall (2015) outlines that migrants practice "everyday resistance", transforming London streets into platforms of "shared discontent" (859) and learning multiple languages to allow for strategic economic networking. Framing her study through active migrant participation, as opposed to migration as a process simply "carried out by migrants and regulated by the states" (865) provides a key framework in looking at the immigrant urban space relationship.

This literature review gives rise to questions such as: In what spaces do young immigrant women feel they belong? What dimensions does being a young immigrant woman add to intersectional discussions of space? How does mobility affect young immigrant women? What is the link between identity, transition, and adapting to new spaces? These questions show the need to unpack how young immigrant women socially construct space in Halifax.

\section{Methods: 'A Picture is Worth a Thousand Words'}

This study employs photo-elicitation interviews to gather material through women's idiosyncratic visualizations. In photo-elicitation interviews, participants take photos that are used later as interview stimuli. As opposed to purely verbal interviews, interviews using photographs work to stimulate memories of participants in unique ways (Clark-Ibanez 2004), allowing participants to "reflect on related but indirect associations with the photographs themselves" (1513) and reveal meanings that would otherwise remained hidden. Photos make visible the complexities of everyday life, existing as visual inventories of objects and intimacies, extension of the social, and "connect one's self to society, culture or history" (ClarkIbanez 2004, 1511). Thus, this study used photos to anchor experiences and complexities in and of space.

I followed four phases in the photo interview process as structured by Kolb (2008). The opening phase included a brief meeting or email exchange with interested women in order to introduce myself and the photo prompts, discuss aims of the research, and go through the informed consent process. In the active photo shooting phase, participants took photos of their daily lives in urban space over the course of three days in Halifax. Participants also used old photos in order to incorporate spaces they were not able to visit during the period of data collection. In the decoding phase, participants met with me to discuss the meaning and experiences associated with their photos in a semi-structured interview. In the final stage, analytical scientific interpretation, I coded data according to my key concepts, such as belonging, mobility, identity, and safety, but also left categories for codifying the interviews to "emerge from the empirical data itself" (Kolb 2008).

I locate my study in Halifax, Nova Scotia as a microcosm of broader immigration trends to small cities in Canada. According to the National Household Survey (Statistics Canada 2013), 8,305 (or 29 per cent) of Halifax's total immigrant population of 31,245 arrived between 2006 and 2011. This is an increase of more than 50 per cent on the number of newcomers who arrived between 2001 and 2005. Of the 8,305 immigrants arriving in Halifax between 2006 and 2011, 46 per cent are women, and 14.5 per cent of those women were aged between 15 and 24 at the time of immigration. Within this segment of the population, I recruited eight participants using snowball sampling, a recruitment strategy that builds trust between researcher and participant by "introduction through a trusted social network" (Woodley and Lockard 2016, 377). In order to vary the countries of origin amongst participants, I also distributed flyers, visited community and religious organizations, and created online postings. 
All women included in my study are 18-25 years of age, have university degrees or are university students (although this was not a criteria of participation), are able to engage in conversational English, and have arrived in Canada in the past five years. Participants include two women from the Philippines, two from Kuwait, and one each from Mexico, Egypt, U.S.A, and China. All are from large urban centres. To ensure confidentiality, women either chose or were given a pseudonym. Any potential identifiers have been concealed, photos have been printed with permission of the photographer, and faces have been blurred.

Due to scope and feasibility, I only conducted interviews, and not observations. This, of course, means I only know what people say about space and not necessarily what people do in practice. Nonetheless, photo-elicitation interviews created a participatory process that generated rich data. Photo-elicitation methodologies can "disrupt some of the power dynamics involved with regular interviews" and "empower the interviewee" (Clark-Ibanez 2004, 1512-1513). Participants dictated the content discussed during the interview through their photos, enabling them to talk about what spaces they found important and valuable in their lives. Furthermore, the participatory nature of this method required frequent contact throughout data collection, allowing rapport to be built in a way that exceeds single semi-structured interviews. When a participant and I looked at the photos together, there was always a reason, story, or experience behind why she chose that photo. The photos chosen by women anchored experiences in a meaningful way and triggered memories that facilitated discussion. Using a method that allowed young immigrant women to lead the interviews through photos established a platform that highlights their voices and the particular stories they want to be heard.

\section{Findings}

\section{Freedom, Risk, and Gender}

All the women I spoke to interpret urban space to some degree through threatening experiences as well as through gendered risk perceptions. By risk perceptions, I mean the way in which women assess space as safe or not safe, and to what degree. Awareness, perception, and management of risk inform how we live our lives and make social relationships, and what spaces we occupy (Green and Singleton 2006). Through risk perception and assessment, processes made necessary by gender, spaces are often interpreted as threatening, and as a result, avoided. For the majority of participants, memories of gendered, threatening experiences instil spaces with fear and influence how they assess their safety in space. This exemplifies that risk assessment and perception are spatially located.

Participants in this study perceive themselves as vulnerable in certain spaces as a result of their gender. This is reflected by May, who moved from China 5 years ago, telling me a story about a man who verbally harassed her while she waited for her bus. May said that this man had been consistently verbally harassing young Asian women around Halifax, stating, "we don't know how to protect ourselves or how to defend [ourselves], so...that's the most scary part."

Having only been in Halifax for a year, May had never experienced this type of verbal harassment in China. This left her feeling more vulnerable to the situation. Unsure of how to report the situation, and unfamiliar with resources available to her, May responded to this experience by avoiding the space. Zoey, an Asian-American from The United States, had a similar experience of racialized verbal harassment in public space. As she told me, "Men only come up to me, I don't know to be like 'I like Asians!' or something you know, that kind of weird stuff. Which definitely makes me feel unsafe." Like May, Zoey has encountered racialized verbal harassment for the first time in Halifax. Feeling vulnerable and ill equipped as women in urban space was a consistent theme in all interviews. Mutya feels "cautious" and uneasy on public transport. Lily avoids certain spaces when it gets dark. Maria started putting her bag on her lap to block access to her body when she heard about a case of sexual harassment on Halifax busses, and Nina states, "if I were a man than I would probably feel more confident walking down the street 'cause I wouldn't feel threatened by anything." Risk 
perception and feeling vulnerable in space goes beyond sensory interpretations, directly affecting women's feelings towards space, as well as how they move through it. For May and Zoey, and many of women I spoke to, how to assess risk and how to respond to these incidents (during the incident and after, such as finding out what resources are available for support and reporting the event) have become additional learned parts of their new urban lives.

Interestingly, there is a tension between gendered safety issues and the newfound spatial freedom some women have in Halifax. While some participants value having the freedom to occupy spaces they could not in their home country, often due to their gender, the majority of women also feel unsafe in the spaces where they feel free. Coming from Egypt, Lily feels she is gaining independence by walking outside by herself, stating, "In Egypt, there's no way a woman can walk [outside]. You get, you know, verbal kind of comments. You don't feel comfortable walking down the street. But here, it's something I value so much, the privilege of being able to walk from one place to another." Lily also values networking events for career development that she could not attend in Egypt. However, she also feels threatened walking alone on the streets after 9pm and cornered in the small spaces where networking events are often held. May expresses the importance of accessibility to public transport, because it allows her to get to the important social spaces in her life, yet, the bus stop is also where she experienced verbal, racial harassment. The nightclub where Zoey expresses herself through dance and "doesn't feel judged" is also where she feels unsafe and cornered by men asking what race she is. These tensions were prominent in majority of interviews when discussing photos of spaces women feel free and independent.

An additional tension is present between new freedoms of mobility and the spatial restrictions of mobility they face as women. All participants express that since immigrating to Canada they have gained independence through increased mobile freedom in comparison to their home country. This includes accessibility to public transport, occupying public space, and the privilege of walking alone on the streets. However, they all also express the limitations of mobility they face as a result of their gender. Participants' mobility is restricted by what time of day it is, resulting in the avoidance of spaces at night; therefore, altering their everyday lives in space. Maria, who immigrated from the Philippines two years ago, told me she doesn't like going to certain places "especially at night," continuing with, "you know the feeling?" The majority of women I spoke to referenced this "feeling" as a result of being in space at night as a woman, as Lily explained to me:

I don't think [men] are scared of darkness. I feel like women are much more scared of the concept of darkness. We just feel like people can take advantage of darkness. We feel like physically we're not fit to be stronger. So it would be the physical ability that gives you that vibe, what time of day it is gives you that vibe, and the space also where you are... So, if you're like, at a park or if you're at the club, gives you those kind of vibes as well. Who you're surrounded with, what kind of state of mind are people in.

Nina, who immigrated from Kuwait three years ago, is scared to take cabs back home or walk the streets alone at night. Rosa states, "these spaces at night, you have to be a bit more careful if you're a woman than if you're a man." Gendered risk perceptions thus influence these women's mobility and spatial realities, including who they share space with, how they feel in space, and what spaces they occupy.

Despite their risk perceptions, spatial avoidance, and threatening experiences, all participants said that overall, they feel safe in Halifax. Initially, I was surprised by this consensus, given the frightening situations endured by some. How do all of these women maintain a sense of safety in Halifax, despite risk perceptions, fear, or threatening experiences they have told me? The answer is that in order to settle in their new cities, immigrants must learn how to physically and socially navigate the new space in order to develop "the new social and spatial networks 
that will allow them to feel connected, committed, and rooted in a new place" (Rahder and McLean 2013, 161).

For these newcomer women, this important spatial knowledge is developed every day as they frequently occupy new public spaces, try out new restaurants with friends, explore new areas of the city, take public transport, and wander alone in public parks (see Figures 1 and 2). Through regular occupation and participation in the urban landscape, they actively build new spatial knowledge, familiarity, confidence, and in turn, socially construct safe space. As Zoey told me:

Normally I find [when I'm] outside walking by myself I don't feel unsafe in general. Mostly because I'm more at ease with nature [and] being by myself. I like having open public spaces and being able to use them and wander around in them. [...] Even walking from my house to downtown. Just being able to do that. I don't feel unsafe so it makes it way more pleasant for me to live here.

May echoes this, stating, "I like Halifax. Besides, I think I'm more familiar here so I'm not worried about, like, safety issues." All the women I spoke to emphasized the importance of learning the city through exploration because it enables them to gain familiarity and spatial knowledge.

When asked what advice they would give to other young immigrant women, most participants told me that exploring the city, 'putting yourself out there', and experiencing all parts of Halifax were of utmost importance. This was illuminated by Lily's re-
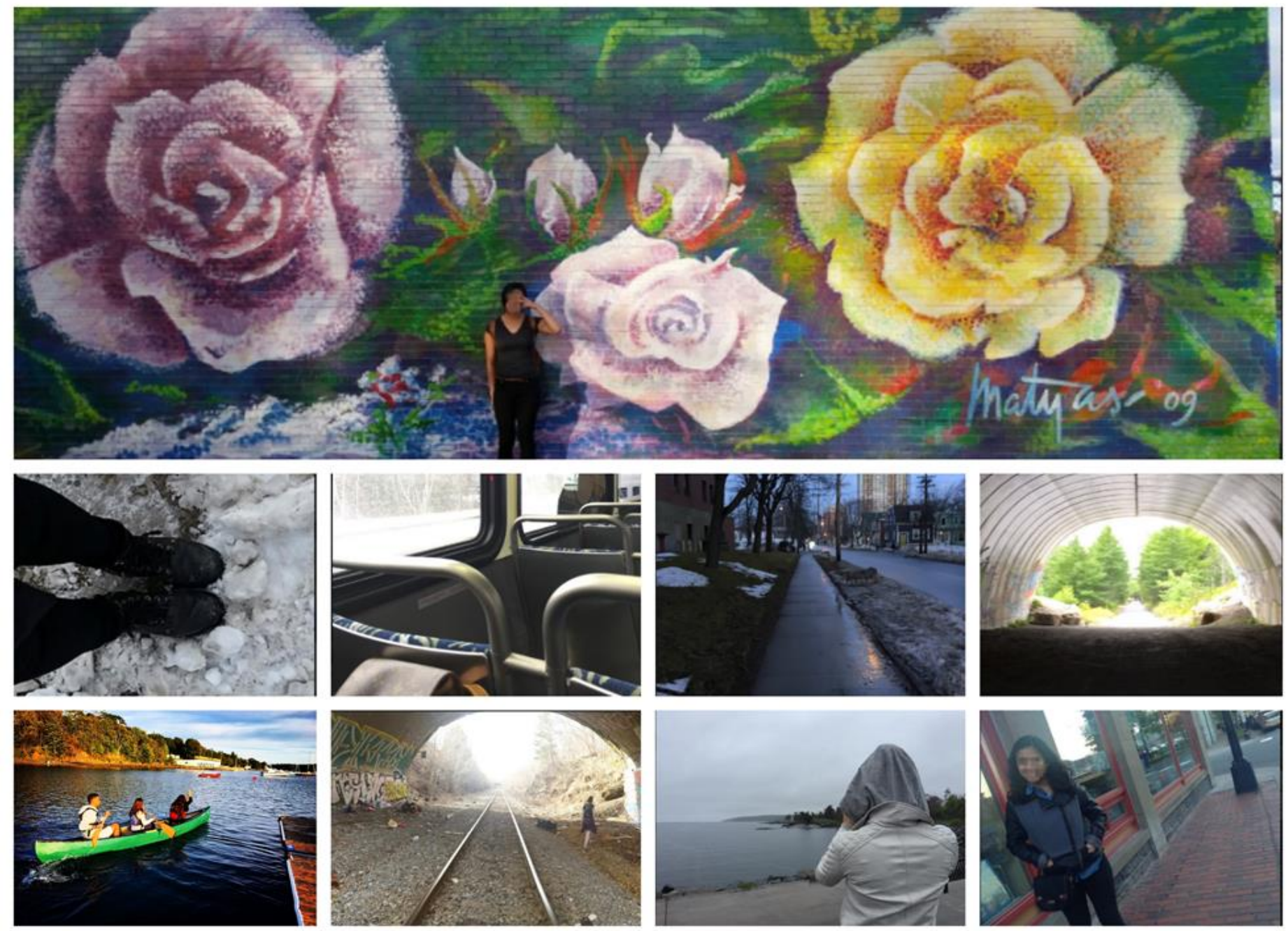

Figure 1. Photos of exploration. Source: Reproduced with permission from anonymous participants. 
sponse when asked what her advice would be for other young immigrant women, stating, "Take every opportunity to walk and explore the city. There's no way you can explore it if you don't walk around spaces to feel comfortable and secure." Zoey expresses that spatial knowledge is important to feeling like she fits in, Maria develops spatial knowledge through public transport, and Lily explores different parts of Halifax through volunteering. Developing spatial knowledge through exploring the city and getting involved transforms spaces to be familiar and safe, as Nina highlights, "If you can go into that space and continue exploring, then you just get used to it and it becomes- it stops being new; it just becomes part of your life."

This emphasis on exploring is linked to the transitionary life stages of immigration and age, as exemplified by Mutya from The Philippines, "There's so much to explore. When I got here everything is new. So I wanted to discover it. So that makes me go out more, right? When you're younger you want to go out and try a lot of things. Maybe it has something to do with growing up, too. So I feel like I should go out more. To grow." Mutya continues to state that her parents have "had their fair share of exploration and all that stuff. They're done." Furthermore, when asked why her and her brother experience the city differently to her parents, Nina responds, "because we're young, we're open to trying new things or adapting. But my mom says she's at a point in her life where she doesn't want to change, she wants stability." In line with Skelton's (2013) findings, mobility between spaces is integral for young people to develop independence, form new relationships, try new things, and 'grow up'. However, mobility for young immigrant women is of increased importance, as it allows them to explore new urban spaces and, in turn, gain the spatial knowledge needed to construct safe spaces.

Women negotiate gendered safety issues by constructing spatial confidence and knowledge through exploration and involvement in Halifax. Women are not kept safe by staying inside their homes; rather, spaces become safer through frequent occupation, or as some participants say, 'just getting out there'. These women are not victims of gendered safety issues, risk per- ceptions, or urban fear, nor is Halifax defined by the restrictions these factors bring. Rather, Halifax is primarily a space of excitement, freedom, and exploration where new spaces bring new feelings, new social relationships, and new modes of being. Immigrant women's everyday use of space has the potential to create accessibility for all women, and as Koskela (1997) puts it, "women's spatial confidence can be interpreted as a manifestation of power" (316).

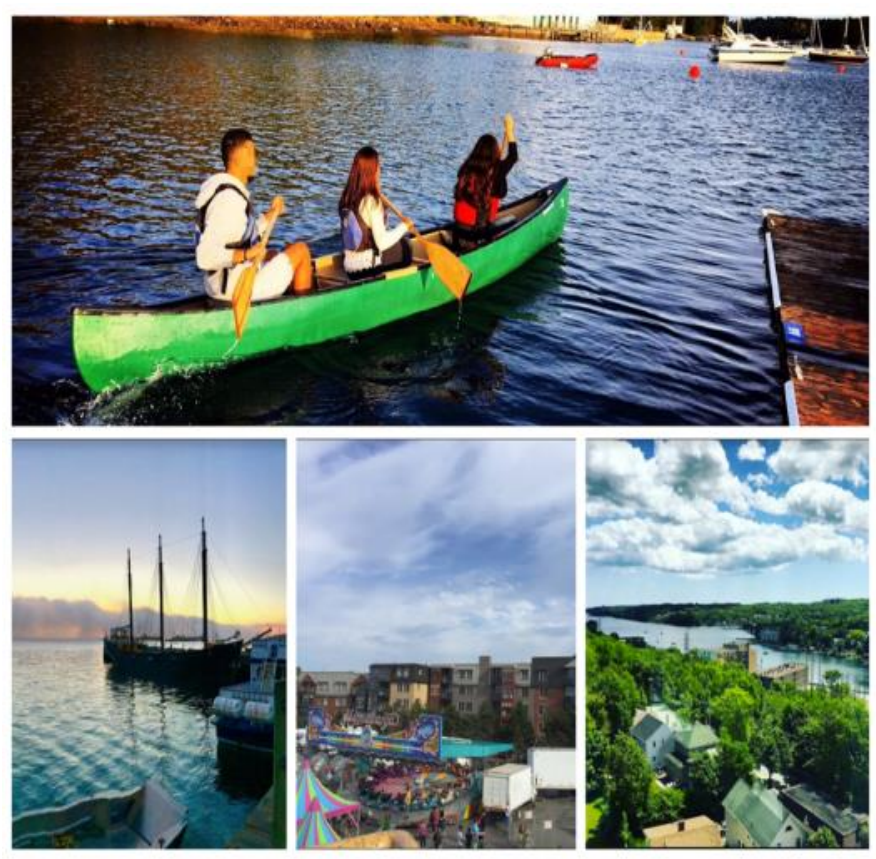

Figure 2. Photos of exploration. Source: Reproduced with permission from anonymous participants.

\section{Feeling 'Out of Place'}

As young immigrant women eat at new restaurants, walk around public spaces, try new activities, relax in nature, and attend university lectures, their everyday lives in urban space are packed with new social encounters and exchanges. All the women I spoke to have felt Othered in some way while interacting with the dominant, white Eurocentric culture in Halifax, meaning they feel treated or perceived as fundamentally different, or 'alien', against the dominant culture and race.

May and Lily explain that feeling like an Other is a result of cultural difference. For example, Lily expresses that her encounters with Canadians create Otherness through fear of judgement, stating, "Culturally, I feel there's a huge difference between Canadians and immigrants in general. I feel like we have that... fear of be- 
ing judged." May, who works at a residence hall at her University, feels residents don't take her seriously because she is Chinese, stating, "If you explain [the code of conduct] to them, they don't care and they don't want to listen to you because oh, uh because uh, 'you're a Chinese person' and 'what do you know about Canada?' I think it happens to lots of immigrants." Feeling pressured to be similar to her coworkers due to the lack of diversity, Maria has felt like an Other in her workplace. When asked how being an immigrant relates to her workplace, Maria responded, "At first I felt it was a threat. I've never felt so bad about myself." She told me that she used to feel threatened when white, older people would come up to her to ask where she is from based on her appearance, but felt pressure to adapt Western customer service behaviours in the space. The experience of Otherness when being "called out" was also felt by Zoey, who feels reduced to race when people ask her unwarranted questions about what race she is, or where she is from. Zoey told me that these challenging moments of Otherness have resulted in negative memories attaching themselves to those spaces. Whether it's judgement from cultural difference or not being taken seriously at the workplace, being made to embody Otherness affects how the research participants feel in space. These examples show that encountering the non-immigrant Canadian majority population in public spaces can often mean being "called out" for visible difference.

Rosa and Mutya have both felt "outcast" in a university setting. Describing her first few weeks of university, Mutya states, "I noticed people didn't want to sit next to me. I don't know if it's because I'm not- I didn't want to assume, that's bad. You don't want to assume that people are being racist to you." Rosa sometimes feels intimidated attending her mostly "all -white gym," and experiences moments of isolation when she has to explain how to pronounce her name, stating, "It's a little-- maybe like outcasting? Obviously not on purpose, and nobody's trying to outcast me, but it feels weird to have to repeat your name or answer the question 'oh where are you from?'" Rosa also explained her challenges contending with discrimination in Halifax, stating:
I think we experience much more discrimination in a way because we're not Canadian, even though we might look the same, or like, the people that are Canadian don't all look 'Canadian'. But I think our culture is very different from here so how we experience things is very different from how people that are born here experience things, right? Plus, when in Mexico, for example, everyone was like me and everyone looked like me, so coming here it's also very... it's a different experience [compared to] someone that was born here.

In this way, Rosa highlights that both visible appearance and 'invisible' cultural differences define how she encounters power in space.

Nina has experienced various moments of Otherness as an immigrant, one of which occurred while walking around Halifax, where a man yelled at her to leave the country. Undoubtedly, this overt verbal discrimination made Nina feel like an Other. However, she also told me less explicit instances of encountering Otherness. Nina said she feels "out of place" being around people drinking, being in spaces in Kuwait where rich people go, visiting spaces in Jordan and Lebanon where "members of a certain sect frequent", and lastly, as she states, "sometimes when I don't see people who are similar to me I feel out of place. Like maybe I'm not supposed to be here, maybe this place is not for me." Nina also describes feeling like an Other due to her hijab, stating, "I do feel kind of uncomfortable. My hijab, for example. If I go to, let's say, a restaurant where there aren't people wearing hijab or where there are people drinking or something, then I would feel kind of restricted. Well, not really restricted, but, what's the word? Like, I would feel that I shouldn't be there." Whether marked by class difference in Kuwait, belonging to a different sect in Jordan, or being a visible minority in Halifax, feeling out of place is something she has experienced in every country she has lived. However, each moment of 'displacement' is constructed by different contexts and each affects the way in which Nina experiences space, what spaces she chooses to occupy, and whether she feels like 

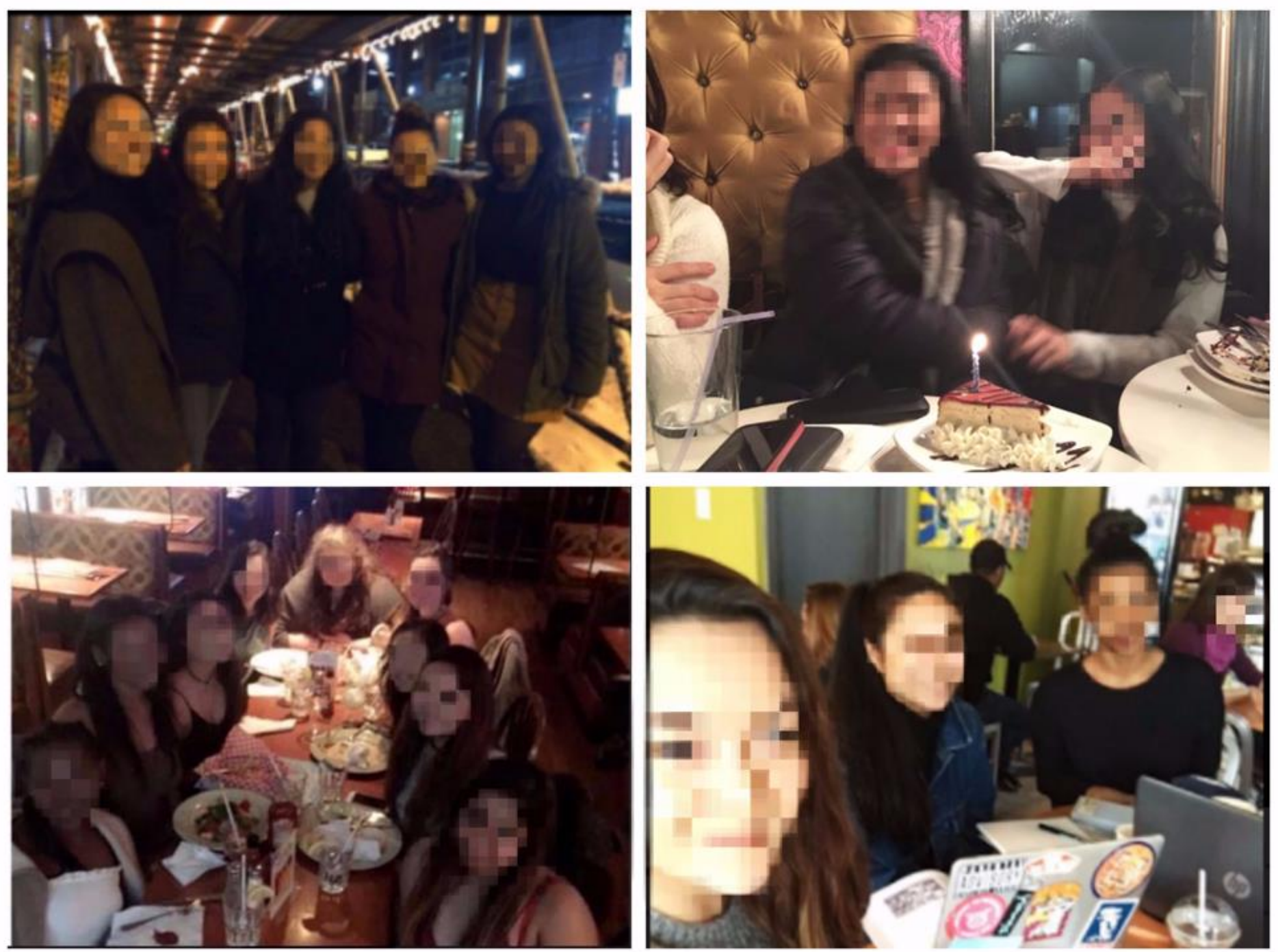

Figure 3. Participants and their social networks. Source: Reproduced with permission from anonymous participants.

she belongs. In general, although participants recounted only a few explicit experiences of discrimination, most articulated an awareness of their position as an Other in urban spaces, and therefore always potentially subject to discrimination and racism.

All young immigrant women I spoke to encounter Otherness as they experience new spaces. However, these women also actively negotiate these everyday encounters with Otherness. One way they do this is by finding unity in diversity, or being "together-indifference" (Ang 2003), through building ethnically diverse social networks. Every woman I spoke to had a friend group composed of other immigrants or international students, or friends of similar cultural origins (Figure 3). Underlining these international bonds are perceptions of commonality based on shared experiences, understanding, and the absence of judgement. Lily told me she finds a common ground with inter- national people because they share the same experiences, stating, "You would find at least common grounds as to feeling the same way. Feeling like you don't belong at first, you know, going through the same struggles of adapting. [...] Culturally, I feel like I might be judged rather than if I speak to someone, you know, who's been through the same thing." Lily describes this as "an unspoken understanding," a notion that encapsulates how majority of participants justified their international social networks. Participants found comfort and relief in building diverse social networks, as illuminated by Negsti from Kuwait, "I thought that if I didn't find people where I'm from, I'm not gonna fit in. But after a while I met people who were from other places. And, to be able to have conversations or to have things in common with people from different places was great." Furthermore, four participants told me they express themselves through their diverse social networks, no mat- 
ter what spaces they occupy. This illustrates that the construction of belonging is mobile and has the ability to transform spaces to ones of belonging by moving from place to place.
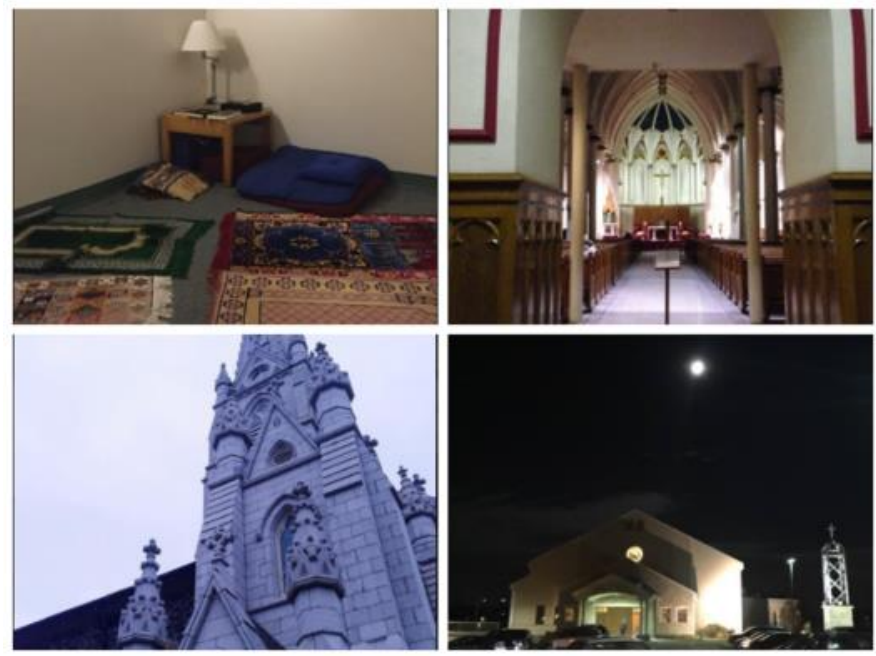

Figure 4. Religious spaces highlighted by participants. Source: Reproduced with permission from anonymous participants.

In addition to constructing belonging through their social networks, participants also actively find, claim and construct spaces that belong to them. They do this primarily through carving out religious space and giving back to the international community. Local churches serve as an avenue for Mutya and Maria to meet diverse groups of people and renew their international social networks (Figure 4). They actively claim this space through renewing their connection to the international community and practicing Filipino rituals. For Nina, the prayer room at her university is more than just a place to pray. Stating that it makes her feel safe because she is "acknowledged as a Muslim in society," and free from judgement, she links that space to a feeling of belonging. Before showing me a photo of the prayer room (Figure 4, top left), Nina states, "Immigrants may be intimidated by these places where they see a lot of um... native people going. Maybe they feel that these places are not for them." Standing in stark contrast to the spaces Nina interprets as "not for immigrants," the prayer room is a space that belongs to her. Massey argues that the "identity of a place is always being produced and reproduced through its processes" (Massey 1994, 171). In line with Massey's argument, these young immigrant women actively shape the identity of space to be spaces of belonging. In other words, by negotiating Otherness through socially constructing belonging in space, young immigrant women also create spaces that belong to them.

Giving back to the international community and forging international bonds are ways in which participants claim space for themselves and larger international communities. For example, three participants find value in helping other immigrants adapt to Canadian life. Working as a resident assistant at her university, May states that she expresses herself through her workplace because, "I always wanted to help international students adapt to Canadian culture and university life in Canada. So I feel like I want to do something for them." Lily, who took a photo of the farmers market for a place that is important to her (Figure 5), told me about her experience working with Syrian refugees to establish a sustainable food business, stating, "It's a space where I feel important because I feel like I have made something happen, I've helped even just for a slight bit." Moreover, Rosa volunteers for the international student society at her university, working to establish a voice for international students on campus. These women actively work to claim and make space for international communities. The spaces where they help international people are used as avenues to situate themselves within their wider community, renew larger international networks, and utilize their own experiences to help others.

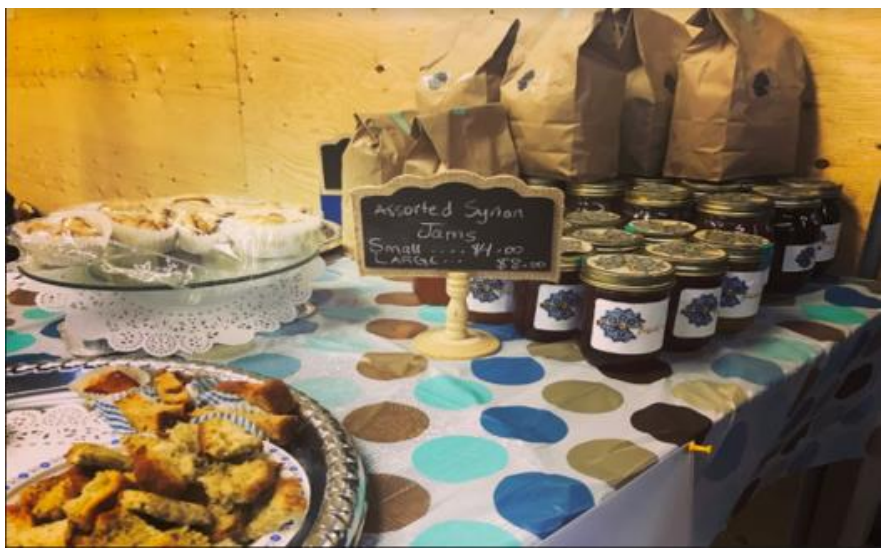

Figure 5. Lily's photo of the farmers market for the prompt 'place that's important to you' Source: Reproduced with permission from an anonymous participant.

Lily, Negsti, and Maria negotiate Otherness by changing their understanding of what it means to be an immigrant in Halifax. These three participants construct everyday belonging 
in space through discovering value in being an immigrant. Negsti sees her cultural background as an asset for getting a job as a translator to help refugee families, and Lily believes her immigrant identity brings a different perspective to her workplace, stating, "I feel like who I am is being rewarded all the time." Maria, who originally felt threatened by customers asking where she's from at her workplace, now sees it as an asset to develop her customer service skills. For these women, belonging is not finding spaces they 'fit in' or becoming more Canadian; rather, they negotiate Otherness by finding value in their identity as an immigrant.

When participants responded to the question of what an ideal space would be for young immigrant women, discussions did not include 'cohesion', 'assimilation' or 'fitting in'. Rather, the majority of participants stated that their ideal space would include "diversity;" "a space to talk to people from different cultures;" "common places for everyone;" "accepting of all people;" and "a collective space where everyone's allowed." When responding to this question, many women were aware of the idealism of their responses. However, their answers also shed light on a different understanding of belonging in and to space. As Mutya disclosed, "I have my Canadian; I have my Filipino, but I'm still me. I'm not completely adapting everything so I'm bringing my own to the table as well." For these women, belonging is not a process of cohesion or integration to Canadian culture; rather, belonging is constructed through everyday processes of diversity in space. In line with Hall's (2015) argument, for these women, belonging is an everyday, participatory process that is "renewed and remade rather than simply accommodated" (865). They are involved in "an active making of new urban spaces" (Hall 2015, 856) and therefore, urban transformation.

\section{Mobilizing Identities: Spaces as Becoming}

According to the literature on gender and space, women's identities are perceived as restricted due to the confined spatial mobility-especially confinement to domestic spacesthat contributes to their subordination (Massey 1994; Rosaldo 1974). However, all participants chose photos of their bedrooms, or homes, as places where they "express themselves," or "feel most themselves." As participants told me, this transitionary period of their lives requires them to perform new understandings of gender, perform "maturity" at their jobs, speak English, and perform new cultural behaviours in order to "adapt". Some participants expressed that part of understanding space involves observing how people act within it, and adopting those new learned behaviours, such as how women dress, how young people socialize, or how people greet each other in the grocery store. Thus, spaces outside are characterized by constant performance. Home, however, is a refuge from this learned spatial performativity, both genderbased and cultural, that young immigrant women feel they must take on. Home is where Mutya dances, Rosa learns about herself, Maria learns new recipes, Nina can take off her hijab, Zoey can finally think clearly, and Lily can speak Arabic with her mother. Home is where identity is both formed and rooted. For these women, home is not where gender roles are located or performed, nor are their identities restricted due to expected domesticity. Home is where performativity is interrupted and identity is explored and refreshed.

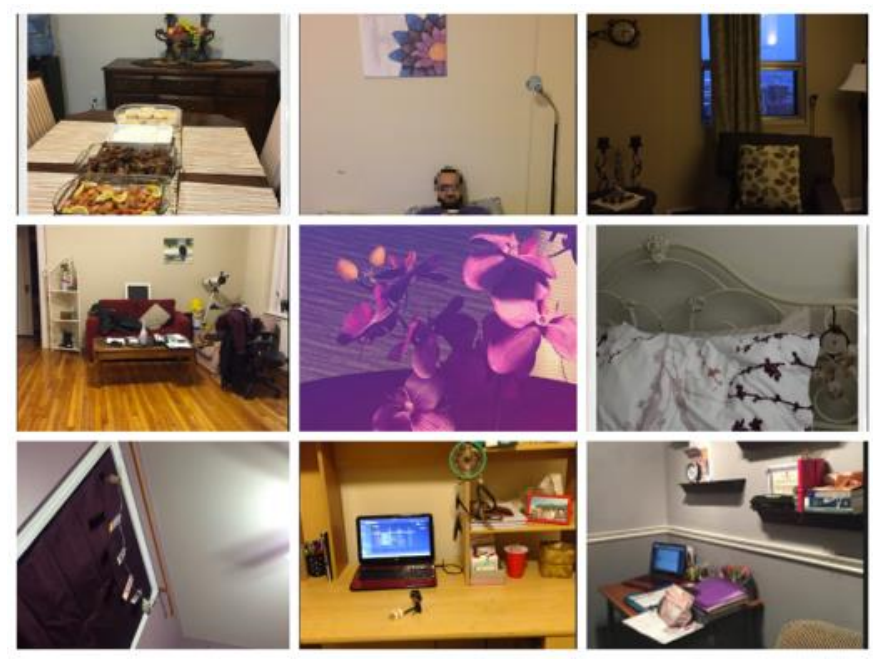

Figure 6. Photos participants chose of their homes and bedrooms. Source: Reproduced with permission from anonymous participants.

Not only are these women new immigrants, but they are also transitioning into adulthood, adapting different ideas of womanhood, trying to find temporary work, places to live, and deciding a career path. Whether it was fear of having to move back to the country they came from, or nervousness about getting a job in Canada as an immigrant, all participants expressed ambivalence or uncertainty in some 


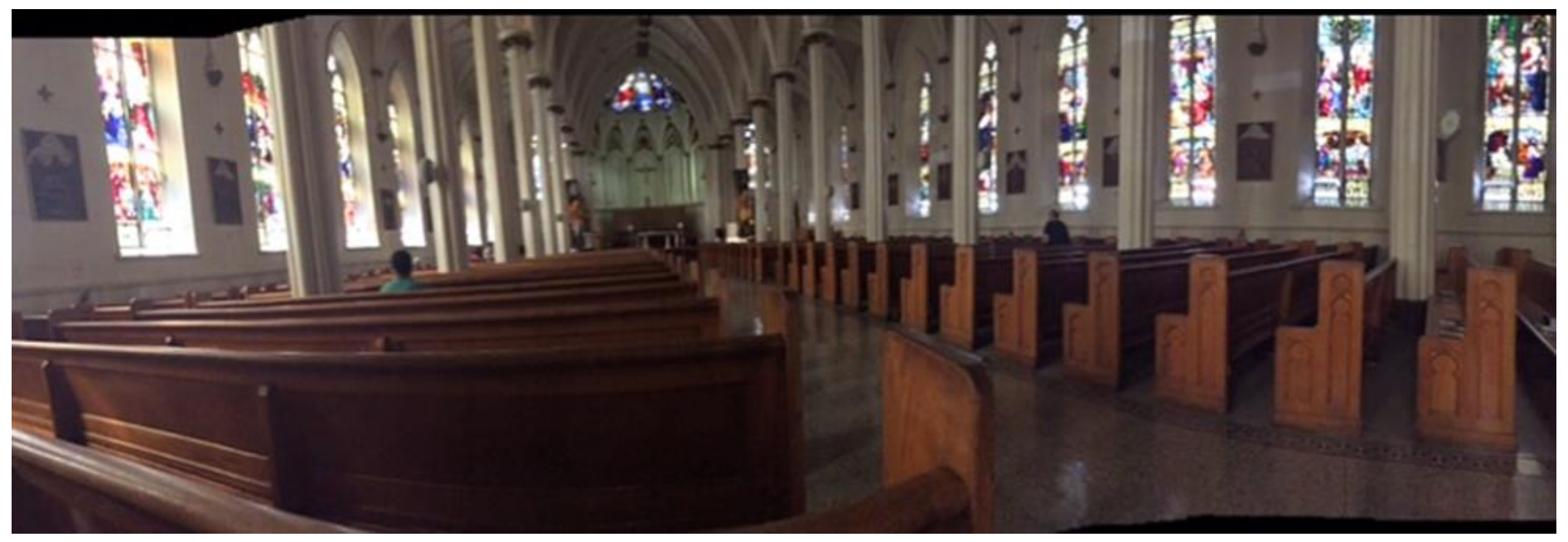

Figure 7. Photo of the church Negsti goes to be alone. Source: Reproduced with permission from an anonymous participant.

way. In response to this uncertainty, an evident theme throughout the interviews was seeking spaces of stillness and control. Participants view these still, quiet spaces as separate from the outside world. Often labelled by participants as "my space," these are spaces that are predictable, in stark contrast to the unpredictable outside world laden with movement and change, as Negsti said about her church: "Outside there's a lot of movement. [Here], you feel like the place is pausing for a moment." In these spaces, they are able to slow time, be in control of their environment, and address the anxieties of adjusting to new environments, negotiating Otherness, and developing new social and gender identities. These are spaces where they can exert some level of control, standing in opposition to the ambivalence that characterizes their lives.

When describing why these spaces are important to them, women told me the following: "It's where I can stay for a while then go back to normal life" (May), "I feel like my room is like my mind. I can think there" (Negsti), "It's where I have that alone time" (Lily), "I pray there, which is a personal expressions of myself" (Maria), "you make it your own place, rather than places outside" (Rosa), "you forget you're in Halifax when you're there, you forget about the world for an hour" (Nina), "I have complete control over it. It's a place you can feel grounded" (Zoey). While these spaces are viewed as quiet and still, even sacred, as May told me about her piano room (Figure 8, top left), they are still moving. These still, quiet spaces are where the processes of identity formation are at work. Participants disclosed that these spaces are where they learn about themselves and find, as many state, "time for myself," "freedom," and "space to think." When photos of these spaces were discussed, conversations revolved around how they are spaces for themselves. These spaces are where participants express themselves, pray, study, paint, try new things, and speak to friends from their home country. While these women may experience their secluded spaces as immobile and unchanging, they still embody movement through the processes of identity formation. In line with Massey's argument, even if space is perceived as still, place is not being-- it is always becoming.

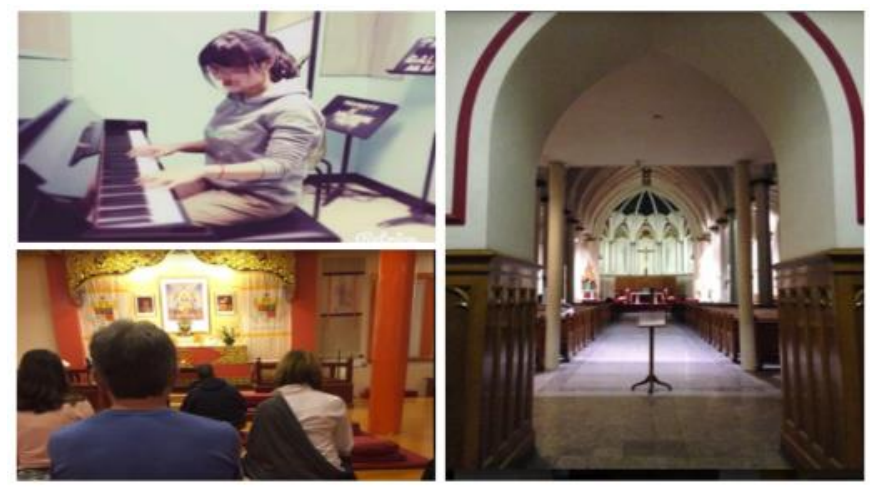

Figure 8. Spaces of seclusion and stillness. Source: Reproduced with permission from anonymous participants.

Participants expressed the need to connect to their cultural identity upon immigrating to Canada. This need to access and mobilize their new identities as immigrants is facilitated by certain spaces. Mobilizing different dimensions of their "old selves" and maintaining a connec- 
tion to their cultural heritage through space is important for all participants. This is exemplified by Maria, who accesses her cultural identity through attending Church with other Filipinos, stating, "When I'm there I just feel like I'm myself again, like a part of myself is actually still alive even if I don't feel it. [...] Sometimes the world is just running right... it's going and you tend to forget some things that are of value to you." These women use different spaces to act on different dimensions of their identities, with some spaces highlighting the formation of their new identities as immigrants. Four participants connect to their cultural identities at home, where they can speak their language, cook food from their home countries, and connect with their families. May accesses this part of her identity through helping other international students adapt to Canadian life at work, or as she states, "I found myself." Furthermore, as Mutya states:

The only time I feel I'm an immigrant is when I have to get in touch with my Filipino roots. But I don't see it as a negative thing because I'm gonna stay here and eventually I want to be a Canadian. But at the same time, I'm taking both of my identities with me. It's like a mixture of both. I miss my home and everything, and a lot of things that I do is - it still has to do with my being Filipino. But I don't see it as a negative thing. It makes me different, but it's not something bad. The word immigrant is kind of getting to me I guess, because this is my home now. I'm gonna live here. I'm not planning on going back.

Mutya also highlights that eating at Filipino restaurants, or attending events where Filipinos gather, are a way for her to act on her cultural identity, and therefore her identity as an immigrant. Accessing and forming an immigrant identity is important in their integration to Canadian cities. Furthermore, Rosa and Negsti both desire more spaces where they can express their cultural identity through sharing culture, traditions, spices, clothes, and customs. It is important to note that the context of being in Canada shapes how immigrants express identi- ties or address their heritage because the policy of multiculturalism officially validates it. This is exemplified by Lily's belief that being an immigrant in Canada is an asset in her career development compared to other countries. Thus, the need to share one's culture may play out differently in a country where there isn't an explicit recognition of multiculturalism.

The women I spoke to form new definitions of gender identities and what they view to be adult and 'Canadian' identities. An important component to accessing and mobilizing new understandings of themselves is their life stage, where new identities must be formed in order to 'grow up' and 'adapt'. All aged between 18-25, many of the participants work to carve out parts of themselves that exist separately from their parents. Many believe that moving to Canada has allowed them to 'grow up' in different ways than they would in their home country, as May states:

I think the main thing I learned in Canada is that I know more about myself because in China you're always a child. You're a child, all the time! Even though people thirty or forty or so, they're still a child to their parents, their grandparents, their families. So you never get a chance to really... be yourself. Or be an adult. An independent adult. Back in China I'm always the "good girl," but that's not what I want to be forever. Every time I go back [to China] they say 'oh you're more mature now; you're an adult! You're not a girl anymore!' and I feel proud of myself because they treat me differently so they don't treat me as a little girl, they treat me as a young adult with my own thoughts.

This quote reflects the thoughts and feelings of all participants, who expressed that they are more outgoing, confident, and independent as a result of the new spaces they are able to occupy and activities they do in them. They are now able to live alone, get part time jobs, hang out in public spaces, establish new social identities, and have freedom from parents who previously dictated what spaces they occupied. Observing Western women in urban space has al- 

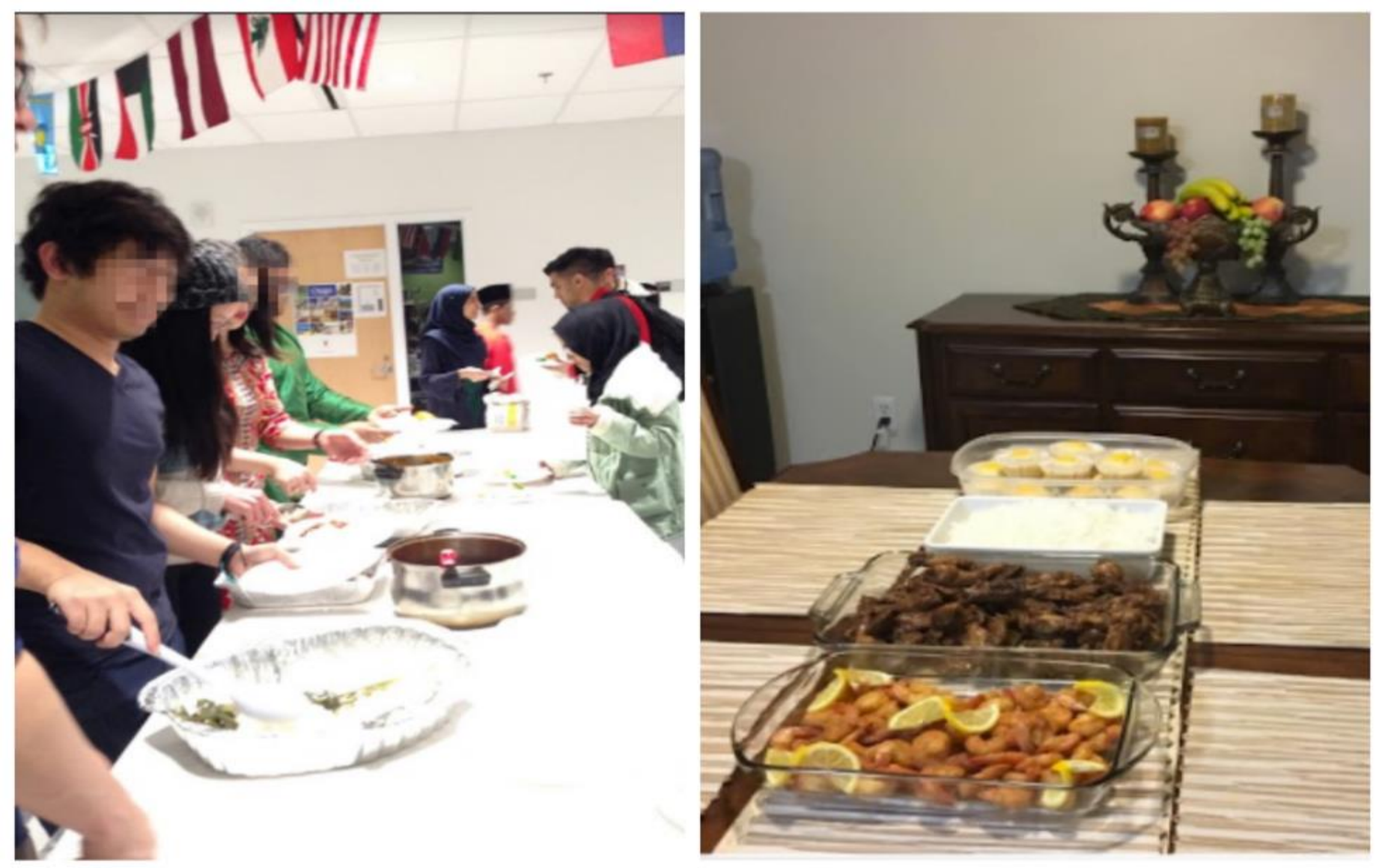

Figure 9. Photos where participants express cultural identity. Source: Reproduced with permission from anonymous participants.

so brought new understandings of gender identity and performance, with many participants stating they have become "less conservative" than they were in their home countries. Many women share the belief that if they were to stay in their country of origin, they would not have developed in the same way. May believes her life has changed because the primary goal for young women in China is to find a good husband. Negsti expressed that living on her own is a privilege, as she could only move out as a woman in Kuwait if she got married. Furthermore, when asked if her life would have followed in the same direction if she stayed in Egypt, Lily replied, "Knowing how I came here to Canada, I would have been much more closed and struggling with interacting with strangers. I wouldn't have met someone like you, for example. That outgoing personality I have right now wouldn't have been developed at all." While all participants view these changes as positive, it is important to note that these changes are linked to perceptions of who women think they should be within their new urban landscapes (an independent 'Western' woman). As these young im- migrant women contend with new spaces, they also form new social identities and understandings of themselves as a result of their life stage.

\section{Conclusion}

This study unpacks how young immigrant women actively transform their city against a foreground of inequality and racialized contexts, revealing the social construction of space to be at the core of their urban experiences. First, I have emphasized two tensions experienced by participants in space; one being between newfound spatial freedom and gendered safety issues, and the second between freedom of mobility and the spatial restrictions they face as women. I argue that young immigrant women negotiate gendered safety issues through the development of spatial knowledge and through these processes, help transform spaces to be accessible to al/ women. Second, I outlined the diverse ways in which young immigrant women experience Otherness in space. What's emphasized here, however, is that they actively negotiate this Otherness by constructing belonging and claiming spaces. 
After examining how young immigrant women shape the city, I analyzed why women chose their bedrooms, homes, or secluded spaces as where identity manifests. I discovered that home is a refuge from both the performativity they must adopt and the change that characterizes their life stage. As places where the processes of identity formation are at work, I argue that while perceived as still, these spaces remain in motion. Lastly, I examined how participants act on and mobilize their new identities as immigrants, women, and adults through different spaces.

This study illuminates that young immigrant women are not passive recipients who simply encounter social change, inequality, or new understandings of themselves. Rather, they actively engage in the processes that transform cities through claiming spaces, constructing belonging, negotiating inequality, and acting on different social identities. Young immigrant women are not simply accommodated; rather, they actively weave themselves into the fabric of cities. Addressing the underdeveloped research of young immigrant women in Canadian urban spaces, this study shows that participants' everyday experience of urban space is participatory, active, and negotiated.

Exploring how young immigrant women interpret and experience urban space opens up ways of understanding larger issues involving diversity, inclusion, and identity within cities. Engaging with the 'everyday' social constructions of space builds new understandings of integration, where space is actively claimed and shaped by immigrants. Further research is needed that allows the voices, needs, and perspectives of young immigrant women to be integrated in social research and urban policy. As this study focuses on the everyday, and how people subjectively interpret space, more research is needed that analyzes how young immigrant women in particular are affected by overarching structures of power. It is vital to explore how the institutions of political and economic power that constrain or direct agency influence life for young immigrant women. Furthermore, an analysis that includes young immigrant women and class as a social position is required. Addressing the rise of diversity in cities calls for reframing questions of immigrant integration to consider how spaces are actively claimed and constructed as ones of belonging by immigrants themselves. If cities are to belong to all people, all people must create them. If this is to be achieved, acknowledging that people experience space differently is crucial, and the multiple ways young immigrant women experience space must be incorporated, understood, and acted on by urban policy makers. 


\section{Acknowledgements}

I would like to acknowledge the Dalhousie University Anthropology faculty for investing in students and providing many opportunities to learn and grow. Thank you to Martha Radice for helping me make sense in my writing, in my ideas, and of the world. Your unyielding support has allowed my passion for anthropology to grow more than I could ever expect. Finally, a big thank you to the women who shared their photos, time, and stories with me. Your visions of the city are inspiring and I sincerely wish you all the best building your lives in Canada. 


\section{References}

Ang, Ien. 2003. "Together-In-Difference: Beyond Diaspora, Into Hybridity." Asian Studies Review 27 (2): 141-154.

Brettell, Caroline B., and Carolyn F. Sargent. 2013. "Domestic Worlds and Public Worlds." In Gender in Cross-Cultural Perspective, edited by Caroline. B. Brettell and Carolyn. F. Sargent, 77-80. Boston: Pearson.

Clark-Ibanez, Marisol. 2004. "Framing The Social World with PhotoElicitation Interviews." The American Behavioral Scientist 47 (12): 1507-1525.

Clark, Cindy D. 1999. "The Auto-Driven Interview: A Photographic Viewfinder into Children's Experiences." Visual Sociology 14 (1): 39 -50 .

Giritli-Nygren, Katarina, and Ulrika Schmauch. 2012. “Picturing Inclusive Places in Segregated Spaces: A Participatory Photo Project Conducted by Migrant Women in Sweden." Gender, Place \& Culture 19 (5): 600-614.

Green, Eileen, and Carrie Singleton. 2006. "Risky Bodies at Leisure: Young Women Negotiating Space and Place." Sociology 40 (5): 853-871.

Hall, Suzanne M. 2015. “Migrant Urbanisms: Ordinary Cities and Everyday Resistance." Sociology 49 (5): 853-869.

Kolb, Bettina. 2008. "Involving, Sharing, Analysing-Potential of the Participatory Photo Interview." Forum: Qualitative Social Research 9 (3): 1-25.

Koskela, Hille. 1997. “Bold Walk and Breakings: Women's Spatial Confidence Versus Fear of Violence." Gender, Place and Culture 4 (3): 301-319.

Low, Setha. 1996a. "Spatializing Culture: The Social Production and Social Construction of Public Space in Costa Rica." American Ethnologist 23 (4): 861-879.

Low, Setha. 1996b. "THE ANTHROPOLOGY OF CITIES: Imagining and Theorizing the City." Annual Review of Anthropology 25 (1): 383409.

Massey, Doreen B. 1994. Space, Place, and Gender. Minneapolis, Minnesota: University of Minnesota Press.

Maynard, Mary. 1994. “'Race', Gender and the Concept of 'Difference' 
in Feminist Thought." In The Dynamics of 'Race' and Gender: Some Feminist Interventions, edited by Haleh Afshar and Mary Maynard, 9-25. London: Taylor and Francis.

Maynard, Mary. 2002. "Studying Age, "Race" and Gender: Translating a Research Proposal into a Project." International Journal of Social Research Methodology 5 (1): 31-40.

Nayak, Anoop. 2003. Race, Place and Globalization: Youth Cultures in a Changing World. New York, NY: Berg Publishers.

Rahder, Barbara, and Heather McLean. 2013. “Other Ways of Knowing your Place: Immigrant Women's Experience of Public Space in Toronto." Canadian Journal of Urban Research 22 (1): 145-166.

Rodman, Margaret C. 1992. “Empowering place: Multilocality and Multivocality." American Anthropologist 94 (3): 640-656.

Rosaldo, Michelle Z. 1974. "Women, Culture, and Society: A Theoretical Overview." In Woman, Culture, and Society, edited by Louise Lamphere and Michelle Z. Rosaldo, 17-42. Stanford, CA: University Press.

Skelton, Tracey. 2013. “Young People's Urban Im/Mobilities: Relationality and Identity Formation." Urban Studies 50 (3): 467483.

Statistics Canada. 2011. Immigration and Ethnocultural Diversity in Canada (Catalogue no. 99-010-X2011001). Ottawa, ON: Statistics Canada.

Statistics Canada. 2013. Halifax, RGM, Nova Scotia (Code 1209034) (table). National Household Survey (NHS) Profile. 2011 National Household Survey. Statistics Canada Catalogue no. 99-004-XWE. Ottawa. Released September 11, 2013. http://www12.statcan.gc.ca/nhs-enm/2011/dp-pd/prof/ index.cfm?Lang=E (accessed April 14, 2017).

Statistics Canada. 2016. Notice - Supplementary Information 2017 Immigration Levels Plan. Last updated October 31st, 2017. http:// www.cic.gc.ca/english/department/media/notices/2016-10-31.asp (accessed April 14, 2017).

Woodley, Xeturah M., and Megan Lockard. 2016. "Womanism and Snowball Sampling: Engaging Marginalized Populations in Holistic Research." The Qualitative Report 21 (2): 321-329.

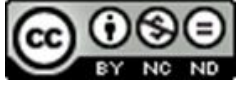

This work is licensed under a Creative Commons Attribution-NonCommercialNoDerivatives 4.0 International License. 